\title{
Pilot study on feasibility of application of gas chromatography for the assessment of acrylamide concentration in sewage sludge*
}

\author{
Elżbieta Włodarczyk ${ }^{1}$, Marta Próba ${ }^{\circledR}{ }^{凶}$, Lidia Wolny ${ }^{1}$ and Łukasz Wojtal² \\ IInstitute of Environmental Engineering, Faculty of Environmental Engineering and Biotechnology, Częstochowa University of Technology, \\ Częstochowa, Poland; ${ }^{2}$ Center for Research and Environmental Control, Katowice, Poland
}

\begin{abstract}
The aim of this study was to determine the possibility of using gas chromatography to measurement of the acrylamide concentration in sewage sludge. Acrylamide, as a toxic substance, is not indifferent to human health, but it is used in the production of plastics, dyes, adhesives, cosmetics, mortar, as well as a coagulant for water treatment, wastewater or sewage sludge conditioning. Determination of acrylamide by gas chromatography was based on standard: EPA Method 8032A "Acrylamid by gas chromatography." It consists of a bromination reaction of the compound in the presence of dibromopropendial derivative, a triple extraction with the ethyl acetate, a concentration of the eluate sample up to the 1 $\mathrm{ml}$ volume, and an analysis by the gas chromatography using an electron capture detector (ECD). The acrylamide concentration of was calculated according to the formula presented in the mentioned standard. All samples were performed twice (the difference between the results was not greater than $10 \%$ ), and the average value of the four samples was $17.64 \mu \mathrm{g} / \mathrm{L}^{-1}$. The presence of acrylamide in sewage sludge has been confirmed.
\end{abstract}

Key words: acrylamide, polyelectrolyte, sewage sludge, gas chromatography

Received: 15 October, 2013; revised: 31 March, 2014; accepted 14 April, 2014; available on-line: 06 June, 2014

\section{INTRODUCTION}

Acrylamide (2-propenamide $\mathrm{CH}_{2}=\mathrm{CH}-\mathrm{CO}-\mathrm{NH}_{2}$ ) is a low molecular weight organic compound containing in its structure conjugated double bonds and a part of the amide. Due to the presence of characteristic functional groups, acrylamide is a polar compound. It is a colorless and an odorless crystalline solid. Acrylamide is well soluble in water and in polar solvents such as methanol or ethanol. It is produced on an industrial scale for 60 years by catalytic hydrolysis of acrylonitrile. Currently, it is used, for the synthesis of modified polyacrylamides, which are used in the industry, during the production of plastics, dyes, adhesives, cosmetics, mortar, as well as a coagulant for water treatment, wastewater or sewage sludge conditioning (Bajdur \& Sułkowski, 1998; Wolski \& Wolny, 2011). The main source of acrylamide contamination in the natural environment are polyacrylamide flocculants, which contain small amounts $(0.5-5 \%)$ of the acrylamide monomer (Jebasingh et al., 2013). The compound is added to the drinking water production plants and to the sewage treatment plants (industrial and municipal). Acrylamide is used mainly in the treatment of groundwater instead of the aluminum ferric sulphate. In Poland acrylamide is used since 1950. The growing presence of acrylamide and its remains in sewage may be caused by the production and consumption of highly processed foods and beverages. The fried food, like fried bread sticks $189.9 \mu \mathrm{g} / \mathrm{kg}^{-1}$ or even egg omelets $350.4 \mu \mathrm{g} / \mathrm{kg}^{-1}$ can be a good example (Zhang et al., 2007).

Acrylamide is an important industrial chemical; however, the International Agency for Research on Cancer has classified this compound as "probably carcinogenic to humans" (IARC). According to the World Health Organization (WHO), permissible concentration of acrylamide in drinking water is equal $0.5 \mu \mathrm{g} / \mathrm{L}^{-1}$. Maximum concentration of this compound in Poland and in the EU is $0.1 \mu \mathrm{g} / \mathrm{L}^{-1}$. Recommended daily amount of acrylamide intake is $100 \mu \mathrm{g}$ per $1 \mathrm{~kg}$ of body weight. In the human body, acrylamide is oxidized to the epoxide glycidamide via an enzymatic reaction using cytochrome P450 $2 \mathrm{E} 1$. Both acrylamide and glycidamide can bind to hemoglobin. The resulting complexes are called hemoglobin adducts, which can be measured in people's blood. (Summer et al., 1999; Hogervorst et al., 2007 ). The various effects of acrylamide pollution include chromosomal abnormalities, cancer, nervous disorders, skin disorders, digestive disorders, circulatory disorders, respiratory disorders, endocrine systems disorders, diseases in humans (Jebasingh et al., 2013). The presence of acrylamide in sewage may cause pollution of the aquatic environment including surface water and drinking water (Malej, 2000; Bień \& Wystalska, 2008; Zawieja et al., 2008). Contamination of drinking water can cause secondary contamination of food, drink and accumulation of the toxic substance in the food chain (Stępniak et al., 2009). Studies on acrylamide in the wastewater were already conducted, however, the complexity and variability of sludge environment still bring a challenge to the analysis of acrylamide (Zawieja et al., 2012; Zawieja, et al., 2013; Wolski \& Zawieja, 2012).

e-mail: marta.proba@tlen.p

* Presented at the 5th Central European Congress of Life Sciences EUROBIOTECH 2013, 8-11 October 2013, Kraków, Poland

Abbreviations: ECD, electron capture detector; EPA, Environmental Protection Agency; GC-ECD, gas chromatography with electron capture detector; LC-MS/MS, liquid chromatography coupled with tandem mass spectrometry 


\section{AIM OF THE STUDY}

Aim of this study was to determine the possibility of using gas chromatography to measurement of the acrylamide concentration in sewage sludge.

\section{MATERIALS AND METHODS}

Reagents and Chemicals. Acrylamide (2-propene amide) was used in research (purity $>99.8 \%$ ) (ICSC, 2006). Solvents used in tests were: ethyl acetate, diethyl ether, methanol, benzene, acetone, distilled water. The following chemicals were also used: bromine water, sodium sulfate, sodium thiosulfate, potassium bromide and hydrobromic acid. All reagents were derived from MERCK Company (analytical grade). The water used in all tests was redistilled and acrylamide-free. To determine whether the distilled water is free of contamination, the blank test was done.

Apparatus. Tests were conducted on gas chromatograph Perkin Elmer Clarus 500 equipped with electron capture detector (GC-ECD) (PerkinElmer, Inc., 2002). Clarus 500 was fully automated gas chromatograph which offered the capabilities to fulfill appropriate gas chromatographic conditions. Nitrogen carrier gas flow rate was equal $40 \mathrm{~mL} / \mathrm{min}$. Column temperature was $165^{\circ} \mathrm{C}$, injector temperature was equal $180^{\circ} \mathrm{C}$ and detector temperature reached $185^{\circ} \mathrm{C}$. Suitable injection volume of sample was $5 \mu \mathrm{L}$. Chromatograph was equipped with electron capture detector, which had an independent temperature range of $100-450^{\circ} \mathrm{C}$. The detector contained thermal protection that prevents heating the $\mathrm{Ni}^{63}$ source to temperatures beyond safe operating limits.

Procedure. Determination of acrylamide by gas chromatography was based on the standard: EPA Method 8032 A "Acrylamid by gas chromatography." Method $8032 \mathrm{~A}$ was used to determine trace amounts of acrylamide monomer in aqueous matrices. To mark acrylamide in the sludge elementary test should be performed with ratio of liquid to solid part equal $10 \mathrm{l} /$ $\mathrm{kg}$ ( $\mathrm{mg} / \mathrm{kg}$ dry weight). Choosen method permits for the determination of acrylamide (2-propenamide) in water in the range from $0.040 \mu \mathrm{g} / \mathrm{L}^{-1}$ to $2.0 \mu \mathrm{g} / \mathrm{L}^{-1}$. This method consists of: a bromination reaction of the compound in the presence of dibromopropendial derivative, an extraction with the ethyl acetate, a concentration of the eluate sample up to the $1 \mathrm{~mL}$ volume, and an analysis by the gas chromatography using the electron capture detector (ECD). The bromination was a first step in the analysis. Dissolved potassium bromide (7.5 g) was treated with hydrobromic acid until $\mathrm{pH}$ was between $1-3$. Next, saturated bromine water was added $(2.5 \mathrm{~mL})$ and sample was placed in a dark place for 1 hour. After that, sodium thiosulfate beeing added, until sample became colorless. Then $15 \mathrm{~g}$ of sodium sulfate was added and sample was stirred. After rinsing with water the sample was extracted three times with $10 \mathrm{~mL}$ of ethyl acetate and dried with $1 \mathrm{~g}$ of sodium sulfate, Next it was rinsed with ethyl acetate. Dimethyl phthalate was added $(100 \mu \mathrm{g})$ to the flask, sample was concentrated up to $1 \mathrm{~mL}$ and injected into the gas chromatograph. Benzene $(50 \mathrm{~mL})$ and solution were added to column chromatography at a flow rate of $3 \mathrm{~mL} / \mathrm{min}^{-1}$. Column was eluted first with $50 \mathrm{~mL}$ of diethyl ether/benzene (1:4) at a flow rate of $5 \mathrm{~mL} / \mathrm{min}^{-1}$, and then with $25 \mathrm{~mL}$ of acetone/ benzene $(2: 1)$ at a flow rate of $2 \mathrm{~mL} / \mathrm{min}^{-1}$. All of the first eluate and the initial $9 \mathrm{~mL}$ portion of the second eluate were discarded, and the remainder was used for the determination, using dimethyl phthalate $\left(4 \mathrm{mg} / \mathrm{L}^{-1}\right)$ as an internal standard. According to the manual of chromatograph software, calibration curve was made (calibration using the internal consistency of the NIST standard (Lot No. 51011).

Calibration is considered as valid if the correlation coefficient is $r \geq 0.99$ and the coefficient of variation method equals $\mathrm{V} \leq 8 \%$.

Sample preparation. The aqueous extract from a sample of wet sludge was done as follows: $200 \mathrm{~g}$ sample was poured with $2000 \mathrm{~mL}$ of distilled water and next the sample was shaken for 24 hours and filtered for analysis. At the same time the content of dry matter was determined (drying a sample at $105 \pm 5^{\circ} \mathrm{C}$ to constant weight). Weight of dry sediment was equal $20.4 \%$ mass of wet sample.

Sample analysis. Concentration of acrylamide was calculated according to the formula set out in the mentioned standard:

$$
\text { Concentration }(\mu \mathrm{g} / \mathrm{L})=\frac{\left(A_{\mathrm{x}}\right)\left(C_{\mathrm{is}}\right)(\mathrm{D})\left(V_{\mathrm{i}}\right)}{\left(\mathrm{A}_{\mathrm{is}}\right)(\overline{\mathrm{RF}})\left(\mathrm{V}_{\mathrm{s}}\right)(1000)}
$$

where:

$A_{X}$, area of the peak for the analyte in the sample. $A_{i s}$, area of the peak for the internal standard. $\mathrm{C}_{\mathrm{is}}$, concentration of the internal standard in the concentrated sample extract is $\left(\mu \mathrm{g} / \mathrm{L}^{-1}\right) . \mathrm{D}$, dilution factor, if the sample or extract was diluted prior to analysis. If no dilution was made, $\mathrm{D}=1$. The dilution factor is always dimensionless. $\mathrm{V}_{\mathrm{i}}$, volume of the extract injected $(\mu \mathrm{L})$. The injection volume for samples and calibration standards must be the same. RF, mean response factor from the initial calibration. $V_{s}$, volume of the aqueous sample extracted or purged $(\mathrm{mL})$. If units of liters $\mathrm{s}$ are used for this term, multiple the results by 1000 .

The 1000 in the denominator represents the number of $\mu \mathrm{L}$ in $1 \mathrm{~mL}$. If the injection $(\mathrm{V})$ is expressed in $\mathrm{mL}$, then the 1000 may be omitted (U.S. EPA 1996).

\section{RESULTS AND DISCUSSION}

Results obtained from aqueous extract of sewage sludge were ranged from $15.21 \mu \mathrm{g} / \mathrm{L}^{-1}$ to $20.13 \mu \mathrm{g} / \mathrm{L}^{-1}$. Based on the dry matter content a conversion factor was calculated. This factor was taken into account when results of the analysis were calculated: $100 / 20.44=4.9$, and each result was multiplied by this factor (Table 1). The mean value was equal $86.47 \mu \mathrm{gg}^{-1}$ (Fig. 1). The standard deviation was equal to 2.12 .

Tested samples were enriched, and recoveries were 0.99 L. Limit of detection was equal $0.024 \mu \mathrm{g} \mathrm{L} \mathrm{L}^{-1}$, and limit of quantification was $0.04 \mu \mathrm{g} / \mathrm{L}^{-1}$.

Table 1. Acrylamide content in aqueous extract of the sewage sludge in wet sample, and in dry sample.

\begin{tabular}{lll}
\hline & $\begin{array}{l}\text { Acrylamide content in } \\
\text { wet sample }\left(\mu \mathrm{g} / \mathrm{L}^{-1}\right)\end{array}$ & $\begin{array}{l}\text { Acrylamide content in } \\
\text { dry sample }\left(\mu \mathrm{g} / \mathrm{kg}^{-1}\right)^{*}\end{array}$ \\
\hline 1. & 16.81 & 82.37 \\
\hline 2. & 15.21 & 74.53 \\
\hline 3. & 18.44 & 90.36 \\
\hline 4. & 20.13 & 98.64 \\
\hline mean & 17.64 & 86.47 \\
\hline
\end{tabular}

${ }^{*} \mu \mathrm{g} / \mathrm{kg}^{-1}$ of dry weight 


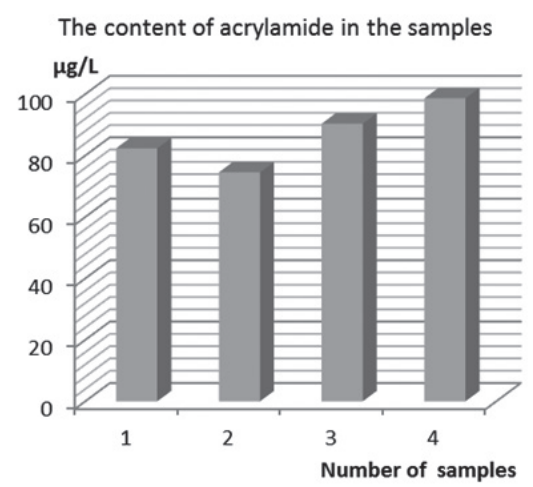

Figure 1. The content of acrylamide in an aqueous extract from municipal sewage sludge.

Results were multiplied by conversion factor for dry sediment.

Since the depolymerization of polyelectrolyte takes place in the presence of sunlight and in outdoor temperatures, acrylamide may contaminate surface water and soil. Such contamination may be hazardous to fish and sensitive aquatic organisms. Especially dangerous is the contamination of drinking water, because in combination with doses of acrylamide in food, the consumed amount of the substance may often exceed the permitted daily dose of the substance. Acrylamide contamination of drinking water and polyelectrolytes used in water treatment may also lead to increased pollution through continuous involvement of substance in the food cycle. A good example could be the beverage industry, where water is the basis of the product and once polluted result in the contamination the whole product. Acrylamide pollution can cause many difficulties such as serological disease to human as well as other organisms. Studies in rodent models have found that acrylamide exposure poses a risk for cancer. However, the evidence from human studies is still incomplete.

The suitability of GC-ECD could be confirmed in future by the certified LC-MS/MS method.

\section{CONCLUSIONS}

This work developed a GC-ECD methodology for the trace quantitative analysis of acrylamide in sewage sludge coming from municipal water treatment. To our best knowledge, these are the first studies using GCECD method dealing with sludge contaminant analysis of acrylamide. High precision and low limit of quantification of the analyte were achieved by this method. There is a need to shorten the duration of the test, in order to increase its availability. Fast analysis could then be employed in a quality control environment closer to production in a manufacturing facility or factory environment, for instance, in the on-line laboratory, allowing for more efficient control and enabling more rapid response if needed. Based on the above method, acrylamide in sewage sludge was analyzed, and relatively low levels of acrylamide were found in all samples.

\section{Acknowledgements}

The authors thank Center for Research and Environmental Control (Katowice, Poland) for providing the guidance of GC-ECD technique. The financial support by Częstochowa University of Technology, Institute of Environmental Engineering (BS/MN-401-319/11, BS/ PB-401-303/12) is gratefully acknowledged.

\section{REFERENCES}

Bajdur W, Sułkowski W (1998) Application of modified polymers as polyelectrolytes, ion exchangers and sorbents. Eng Protect Environ 1: 115-124.

Bień J, Wystalska K (2008) The problems of sewage sludge management. Eng Protect Environ 1: 5-11.

Clarus 500 GC Users Guide (2002) PerkinElmer, Inc.

Hogervorst JG, Schouten LJ, Konings EJ, Goldbohm RA, van den Brandt PA (2007) A prospective study of dietary acrylamide intake and the risk of endometrial, ovarian, and breast cancer. Cancer Epidemiology, Biomarkers and Prevention 16: 2304-2313.

International Agency for Research on Cancer (IARC): IARC Monographs on the Evaluation of Carcinogenic Risks to Humans. (1994) Some Industrial Chemicals, 60, IARC, Lyon, France, 389-433.

International Chemical Safety Cards, Acrylamide, ICSC: 0091 (2006) http://www.cdc.gov/niosh/ipcsneng/neng0091.html.

Jebasingh SEJ, Lakshmikandan M, Rajesh RP, Rajac P (2013) Biodegradation of acrylamide and purification of acrylamidase from newly isolated bacterium Moraxella osloensis MSU11. Int Biodeterior Biodegrad 85: $120-125$

Malej J (2000) Selected problems of sewage sludge processing. Ann Set Environ 2: 39-69.

Summer SCJ, Fennell TR, Moore TA, Chanas B, Gonzalez F, Ghanayem BI (1999) Role of cytochrome P450 2E1 in the metabolism of acrylamide and acrylonitrile in mice. Chem Res Toxicol 12: 1110-1116.

Stępniak L, Stańczyk-Mazanek E, Kępa U (2009) The study on the removal of organic contaminants from water by using ultrasound field. Polish I Environ Studies 2: 62-67.

U.S. Environmental Protection Agency, SW 846, Test methods for evaluating solid waste, Method $8032 \mathrm{~A}$, Acrylamide by gas chromatography, Rev. 1 (1996) Washington D.C.

Wolski P, Wolny L (2011) Effect of disintegration and fermentation on the susceptibility of sewage sludge to dewatering. Ann Set Environ 13: $1697-1706$

Wolski P, Zawieja I (2012) Effect of ultrasound field on dewatering of sewage sludge. Arch Environ Protection 38: 25-31.

Zawieja I, Wolski P, Wolny L (2008) Influence of chemical conditioning on the physicochemical parameters of digested sewage sludge. Eng Protection Environ 11: 387-396.

Zawieja I, Wolski P (2013) Effect of hybrid method of excess sludge disintegration on the increase of their biodegradability. Environ Protect Eng 39: 153-165.

Zawieja I, Wolski P (2012) Effect of thermal disintegration of excess sludge on the effectiveness of hydrolysis process in anaerobic stabilization. Arch Environ Protect 38: 103-114.

Zhang Y, Ren Y, Zhao H, Zhang Y (2007) Determination of acrylamide in Chinese traditional carbohydrate-rich foods using gas chromatography with micro-electron capture detector and isotope dilution liquid chromatography combined with electrospray ionization tandem mass spectrometry. Anal Chimica Acta 584: 322-332. 